DOI 10.37882/2223-2982.2020.04.25

\title{
ВЛИЯНИЕ ПАРИЖСКОЙ ШКОЛЫ НА СТИЛЕВЫЕ НАПРАВЛЕНИЯ В ТВОРЧЕСТВЕ АЛЕКСАНДРЫ ПОВОРИНОЙ-АЛЕРС-ХЕСТЕРМАН
}

\section{THE INFLUENCE OF THE SCHOOL OF PARIS ON THE STYLE OF ALEXANDRA POVORINA-AHLERS-HESTERMANN \\ E. Khlupnova}

Summary: In this work, the author considers the work of a German artist of Russian origin Alexandra Povorina-Ahlers-Hesterman (1885-1963), who left a mark on the cultural heritage of Germany. Born in the Russian Empire, having absorbed the culture of the Slavic spirit, she acquired the fundamental artistic skills in St. Petersburg. The relevance of the work is due to the need to study the cultural heritage of little-known artists of Russian origin, who, for one or another reason, left their homeland. The author analyzed the scientific and fiction literature dedicated to representatives of not only the Paris School but also the New Group of Hamburg artists - "Hamburg Secession."

The work of Alexandra Povorina-Alers-Hesterman developed in the cycle of modernist influences of the early twentieth century in art schools and associations of Europe. The Paris school had a significant impact on the style preferences and the artist's graphic style.

Keywords: school of Paris, cultural heritage, painting, art, Hamburg, abstract art, surrealism.

\author{
Хлупнова Елена Валентиновна \\ Аспирант, Санкт-Петербургский государственный \\ академический институт живописи, скульптуры и \\ архитектуры имени И. Е. Репина \\ при Российской академии художеств, \\ elena.khlup@hotmail.de
}

Аннотация: В настоящей работе автором рассматривается творчество немецкого художника русского происхождения Александры Повориной-АлерсХестерман (1885-1963), оставившей след в культурном наследии Германии. Родившаяся в Российской империи, впитавшая культуру славянского духа, она приобрела первые художественные навыки в Санкт-Петербурге. Актуальность работы обусловлена необходимостью изучения культурного наследия малоизвестных художников русского происхождения, которые по тем или иным причинам покинули Родину.

Автор проанализировал научную и художественную литературу, посвященную представителям не только Парижской школы, но и Новой группы гамбургских художников — «Гамбургского Сецессиона».

Творчество Александры Повориной-Алерс-Хестерман развивалось в круговороте модернистских влияний начала XX века в художественных школах и объединениях Европы. Парижская школа оказала большое влияние на стилевые предпочтения и живописную манеру художницы.

Ключевые слова: Парижская школа, культурное наследие, живопись, искусство, Гамбург, абстракционизм, сюрреализм.

прочно утвердились на художественной сцене, и, разумеется, атмосфера свободолюбивой «столицы мира» давала возможность не только беспрепятственно получать обучение, а также участвовать во всех мероприятиях художественных объединений и салонов.

Что же касается ориентации европейских женщинживописцев на Париж, то вопрос о возможностях обучения и участия в выставках более не играл решающей роли в указанный период, как это было в конце XIX века. Именно флёр новых идей в искусстве, богемная среда и совершенствование влекли соискательниц.

Будучи ядром современности, Париж предлагал широкий спектр для развития: вместе с «Академией Матисса» многие известные и малоизвестные художники давали частные уроки для художников из России, что было предпочтительным, т. к. русская колония Парижа становилась с каждым годом все обширнее. Будучи русскими, они очень скоро могли почувствовать там себя «как дома»: десятки тысяч проживали в Париже до Первой мировой войны; многие из них эмигрировали из-за 
политической эскалации и не предвидели скорого возвращения в родную страну [1, 2].

Художник-график Поворина-Алерс-Хестерман принадлежит к первой волне русской эмиграции и является представителем абстрактного направления в искусстве [3]. Огромное влияние на творчество Повориной-АлерсХестерман оказала Парижская школа и теоретики французского абстракционизма. Долгое время она невольно проецировала в своих работах симпатию к творчеству Матисса и Сезана.

В русских источниках информации практически отсутствуют сведения о творчестве графика $[4,5,6]$. Европа и Германия более подробно изучают наследие художников Парижской школы и наряду с известными, маститыми мастерами открывают новые имена забытых и недооцененных художников. Доктор искусствоведения Анке Мюнстер в своем обширном монографическом исследовании, посвященном жизни и полному описанию работ Повориной-Алерс-Хестерман, пытается разобраться в переплетении судеб, творчества и искусства богемного Парижа, холодного Гамбурга и демократично отстраненного Берлина.

\section{Основы образования Александры Повориной}

Биография Александры Повориной должна начинаться с ее «русской души». Понятие «русской души» романтично и немного превратно, так как «единой» русской души, конечно, не существует. Однако многие идеи художник черпала в интеллектуальных течениях России конца XIX века, которые взращивались и передавались в родительском доме среднего класса, принадлежащем русской «интеллигенции» $[7,8]$.

Александра Андреевна Поворина, родившаяся в Санкт-Петербурге 26 февраля 1885 года, находилась в России не более четверти своей жизни. Долгое время она проживала в Германии, но абсолютное понятие «Дом» она ощутила в Париже и Берлине. При этом ее концепция искусства и жизни неоднократно указывает на ее русские корни. Так, она считала героев Ф.М. Достоевского «великими духовными предками».

Свободное развитие и образование - ключевые слова, наиболее полно описывающие идеалы, царившие в доме родителей Александры Повориной. Использование новых методов обучения характеризует семью с тонкой интеллектуальной настройкой, ориентированную на все новаторское - либеральное. Фактически во второй половине XIX века образование стало для России центральной социальной проблемой, «вопросом жизни» $[9,10]$.

Фундаментальные гуманистические принципы об- суждались на примере воспитания детей, что ставило под сомнение прежнее «распределение власти» в семье. Это также показывает, что в то же время были подняты голоса против строгого патриархального воспитания, угнетения женщин и крепостного права. Примечательно, что в общественной дискуссии о философско-практическом понятии действительно не было педагогов. Писатели, врачи и ученые с различных факультетов разрабатывали различные и многогранные подходы. Нельзя утверждать, что родители Повориной следовали за конкретным автором, когда получали образование. Благодаря хорошему знанию русской литературы мать Повориной была знакома с радикальными педагогическими идеями Л. Толстого. Она немедленно отменила воспитание через угнетение и старалась позволить детям взрослеть только через образование.

Такое амбициозное отношение к воспитанию детей было возможно только в том случае, если семья принадлежала к высшему русскому сословию. Образование в России было привилегией богатых сословий, как и в других европейских странах. Тем не менее есть важное отличие российского образования от образования западных стран Европы. В царской, весьма консервативной России в конце XIX века все больше и больше девушек имели возможность получить образование. В поколении матери Повориной женщины, родившиеся около 1860го г., имели возможность стать исключением и получить интеллектуальное или профессиональное образование для обретения уверенности и поднятия своего социального статуса. В данном контексте было вполне очевидно, что дочери двадцать лет спустя получат профессиональную подготовку. Кроме того, образование для русских женщин стало намного качественнее, и в последствии они могли свободно трудоустроиться, в особенности в гуманитарной сфере. В западной Европе этот вопрос имел малозначительный характер: там образовательные программы для женщин считались поверхностными.

\section{Гамбургский Сешессион}

Александра Поворина сегодня более известна в Гамбурге как участник Гамбургского отделения сецессиона и союза Гедок. Это ирония судьбы, поскольку она не любила Гамбург, не любила жить в этом городе и не имела ничего общего с членами этих групп, за исключением Фридриха Алерс-Хестермана. В Париже, Кельне и Берлине она была практически забыта, но именно здесь она пережила важнейшие моменты становления и развития своего творчества.

Александра Андреевна была инициатором и организатором создания союза художников «Imaginisten». Выбор названия «Воображаемая» не случаен. С одной стороны, нет общепринятого понятия той абстрактной манере, что повлияла на художницу в 1930-е гг. С другой 
стороны, она была крайне заинтересована в создании союза, способствовавшего продвижению стилевого направления и возможности организации выставок, в котором название указывало на стратегию и позиционирование объединения.

Художественное творчество А.А. Повориной характеризует ее работы за пределами различных техник, образных и абстрактных представлений. Особое значение имеют обработка изобразительного пространства, соотношение площади и линии, а также взаимодействие расстояния и близости. Тематическая концентрация и конструктивная работа на ее полотнах делает труды Александры Повориной актуальными для изучения в наше время. В целом ее наследие насчитывает 850 сохранившихся работ, включая более 180-и картин. Смысл жизни и творчества может быть в настоящее время изучен и рассмотрен досконально.

«Искусство - игра и глубокое погружение». Вероятно, по мотивам коллажей Поворина отыскала данное определение собственного творчества незадолго до своей смерти. Эта цитата может обозначать все ее творчество, если поставить «игру» в качестве синонима использования ею творческих средств. В указанном контексте короткое предложение раскрывает диалектику всех ее произведений, неуверенное колебание между независимостью выбора художественных средств и ориентацией на «идеальную» живопись в традиции символизма [3].

За относительно короткий пятилетний период Поворина произвела экстремальные изменения в выборе изображаемых предметов, а также в плане степени абстракции и изобразительного пространства. В связи с этим можно определенно назвать период с 1926-го по 1931-й г. «фазой переориентации». Рассматривая данное развитие с точки зрения мотивов, иконографической композиции и концепции изобразительного пространства, становится ясно, что, несмотря на этот разрыв, в ее работах есть константы. Но, прежде всего, художница нашла для себя ответ на главный художественный вопрос: если в ранних ее работах (пейзажах, портретах и натюрмортах) можно наблюдать художественное пространство, тонко скрытое за мотивом, то теперь ее внимание сосредоточено на увлечении живописным наполнением, не ориентированным на центральную перспективу. Поворина на короткое время отказалась от эскизного наброска и писала «с нуля». Такая система помогла художнику прояснить свой собственный путь. Когда она обнаружила это, написала: «Самое главное делать и позволять писать так, как трактует судьба. Как в современной жизни, так и в произведении искусства спонтанность» [11].

Переходная фаза отлично демонстрирует, что даже в эти годы Поворина не ориентировалась на художественную моду - новую абстракцию, которая уже зарождалась в центре Парижа. Александра Андреевна преобразовала технику и стиль живописи своеобразным способом. Конечно, это не значит, что Поворина экспериментировала в закрытом пространстве. Для нее воплощением художественной модели рисунка был Редон, а в некоторых отвлеченных натюрмортах и трактовке линий можно увидеть конфронтацию с Браком. Она интересовалась его натюрмортами с конца 1920-х гг. Художника впечатляла работа по пространственному расположению, а также прорисовка круглых поверхностей, которые ощущаются как натянутые с квадратных границ картины.

Пикассо к концу 1920-х гг. также уже имеет похожие графические композиции. Поразительно, что другие художники из более поздних участников «Imaginistin» и выставки "Zeit und Zeichen» имеют очень похожую ориентацию в живописи: и Фриц Винтер, и Отто Ритчль интересовались обозначенным нами периодом для синтетического кубизма и таким образом укрепили в своих натюрмортах разные уровни абстракции. Во всех случаях эти понятия укрепились за короткий промежуток времени, что, очевидно, имело важное значение в позиционировании приемов необъективной живописи. Несомненно, натюрморты Повориной сыграли ключевую роль в ее поисках нового художественного пути.

Многие художники из плеяды «создателей абстракционизма» проявляли интерес к явлениям природы и «повторному открытию мира средствами абстрактной живописи». Необычным является конкретное гендерное понимание «воплощения» в таких образах, как «зачатие» или «оплодотворение». Например, у Франтишека Купки (1871-1957; чешский художник, абстракционист) есть некоторые мотивы, отражающие данную тему, но они присутствуют в космическом контексте. Интерес Купки и Повориной к религиям, а также глубокое восхищение эстетическими теориями Гете можно рассматривать как связующий элемент. Художница редко указывала в названии конкретное содержание работы, например: «Из цикла создания». По большей части она ссылалась на элементы дизайна в атрибуции.

Вместе с Отто Ритчль (1885-1976; один из главных представителей абстрактной живописи Германии) в союзе художников, кроме Повориной, состояли еще несколько художников-абстракционистов, которые делали акцент на конкретном именовании содержания работы. Именно Ритчль наиболее точно затронул темы Повориной: «Такие названия, как «Становление», «Человек в мире» и другие показывают, что мышление художника было о его истоках, особенно в тридцатые годы. Все вокруг происхождения макрокосма и кругов микрокосма» [12]. Но из-за значительной утраты работ во время 
войны точные сравнение стали невозможны.

Картины рассматриваемого художника почти диаметрально противоположны сюрреализму, однако не стоит отрицать, что живопись Александры Андреевны имеет точки соприкосновения с данным стилевым направлением. От Макса Эрнста (1891-1976; немецкий и французский авангардист) и Ханса Беллмера (1902-1975; немецкий график, скульптор, иллюстратор, писатель) до французских художников круга Андре Бретона (18961966; французский писатель, поэт, основоположник сюрреализма) художники-сюрреалисты явно исключали аспект возникновения жизни в их исследовании всего сексуального. Можно предположить, что в собственном искусстве они отражали мечты, похоть и навязчивые идеи, по мнению фрейдистов, связанные с психосоматикой.

Поворина преследовал цель: «остановить» зрителя чем-то узнаваемым. Для этого она использовала эмбриональные формы, но в совершенно ином контексте: ее интересовало не происхождение жизни и отношения между родителем и ребенком, а прежде всего - «анатомия вещей, анатомии человека и растений, которые переплетаются» [13].

В этом контексте картины Повориной на тему плодовитости, рождения и смерти, а также метаморфозов бытия можно соотнести с работами Пауля Клее начала 1920-х годов. В дни швейцарского изгнания названия его работ указывают на усиление конфронтации с темами рождения и материнства. Для Клее, однако, эта человеческая концентрация может быть замечена в его работе «Мифический цветок», создании его собственных мифов в романтической традиции. К сожалению, непонятно, знакома ли была Поворина с данной работой, которую высоко ценил сам Клее [14].

\section{Выво $\Delta ы$}

В заключение следует отметить крепкий союз двух художников - Александры Андреевны Повориной и Фридриха Алерс-Хестермана (1882-1973; немецкий художник, историк искусства; муж Александры Повориной), поддерживавших друг друга на протяжении всей жизни. Их творческие амбиции и фатальные события XX века не сломили индивидуальности художников, не разобщили их воззрения на развитие искусства. Их дочь, художница и дизайнер Татьяна Алерс-Хестерман (1919-2000; немецкий художник декоративно-прикладного искусства), стала собирателем живописи родителей и архива семьи.

Каталог работ основан на собрании Татьяны АлерсХестерман, в котором в подавляющем большинстве представлены картины, находящиеся в ее распоряжении, а также в распоряжении ее друзей и коллекционеров. Кроме того, впервые были всесторонне задокументированы графические работы графика, а также коллажи и изделия ручной работы.

Александра Андреевна Поворина-Алерс-Хестерман оставила обширное творческое наследие как немецкий деятель искусства и живописец-график, однако на протяжении всей жизни она всегда идентифицировалась как славянский художник. Начиная с 1914 года, в котором основанием для обвинений в «русскости» значилось русское происхождение, по 1930-е годы А. ПоворинойАлерс-Хестерман приходилось противостоять обвинениям в «коммунистических» мотивах «необъективной» живописи посредством преподавания основ академического рисунка. Неоднократно Поворина выступала пропагандистом русского Высокого стиля, несмотря на поиски новых стилевых средств выражения в живописи.

Поиск себя в искусстве проходил по классическому пути образования. Первые художественные навыки Поворина получила в Санкт-Петербурге. Большое влияние на дальнейшее развитие художника оказала школа Шимона Холлоши (1857-1918; венгерский художник армянского происхождения, педагог). Согласно его учению: «...создание любого произведения искусства (графического или живописного) начинается с построения конструктивной основы изображения, вплоть до обозначения невидимых наблюдателю сторон модели.

Рассматривая влияние школ, стилей и направлений на становление творческой личности, можно отметить, что именно Парижская школа оказала огромное влияние на манеру письма Александры Андреевны Повориной-Алерс-Хестерман. Начиная с поклонения Сезанну, что, скорее, было протестом против немецкого экспрессионизма, художник-график видела развитие авангардистского движения в абстракции, но также очевидно, что ее работы смягчены славянскими воззрениями, заложенными в ее генетическом коде.

\section{ЛИТЕРАТУРА}

1. Толстой А.В. Художники русской эмиграции. — М: Искусство XXI век, 2005. - 382 c. — ISBN: 5-98051-017-2

2. Толстой А.В. Художники русской эмиграции, 2-е изд. — М: Искусство XXI век, 2017. — 384 с. — ISBN: 978-5-98051-165-4

3. Münster, A. "Kunst ist Spiel und tiefer Ernst": Die Imaginistin Alexandra Povòrina (1885-1963), Leben und Werk. Dissertation. — Deutschland, Gießen, 2004. — 
URL: https://www.clio-online.de/webresource/id/webresource-15993 (дата обращения: 20.02.2020).

4. Лейкинд 0.Л., Махров К.В., Северюхин Д.Я. Искусство и архитектура русского зарубежья. [Электронный ресурс]. — Режим доступа: https://artrz.ru/ places/1804916409/1804785858.html (дата обращения: 20.02.2020).

5. Лейкинд 0.Л.; Мохров Л.В.; Северюхен Д.Л. Художники русского зарубежья. Первая и вторая волна эмиграции: Биографический словарь: в двух томах. ө1.—СПб.: Изд. Дом «Міръ», 2019. — 728 c.

6. Лейкинд 0.Л.; Мохров Л.В.; Северюхен Д.Л. Художники русского зарубежья. Первая и вторая волна эмиграции: Биографический словарь: в двух томах. Q2].-СПб.: Изд. Дом «Міръ», 2019. - 852 с.

7. Раев А. Религиозное (под)сознание русских художниц и зрителей. В поисках истоков феномена русской художницы // Амазонки авангарда. Под. ред. Г. Ф. Коваленко; Гос. ин-т искусствознания М-ва культуры РФ. — М.: Наука, 2004. - С. 57-68.

8. Филиппова М.В. Российская эмиграция в культурной жизни Германии в 1920-1933-х гг:. Живопись и театр. — Воронеж, 2001. — 223 с.

9. Kegler D. Das Ethos der Russischen Pädagogik: Studien zum Erziehungsbegriff in Rußland seit Pirogov. — Deutschland, Sankt Augustin, 1991. — 200 S.

10. Chadzis A. Die Malerin und Bildhauerin. Elena Luksch-Makowsky (1878-1967). Biografi und Werbeschreibung. — Deutschland, Hamburg, 2002. — $264 \mathrm{~s}$.

11. Althaus B. Poetik und Poesie des russischen Imaginismus. Anatolij B. Mariengof (Poetica). — Deutschland, Hamburg, 1998. — 221 S. — ISBN: 3860647717

12. Katalog der Ausstellung im Museum Wiesbaden. Deutschland, Wiesbaden, 1997. — S. 35.

13. Колчинский М. Художник и время. Kolchinskij M. Hudozhnik i vremya // Bei uns in Hamburg. Режим доступа: http://beiunsinhamburg.de/2012/hudozhnik-ivremya/ (дата обращения: 31.01.2020).

14. Klee P. In der Maske des Mythos. Katalog der Ausstellung im Haus der Kunst. Deutschland, München, 1999. — S. 133. — ISBN: 3770152360

\footnotetext{
( Хлупнова Елена Валентиновна (elena.khlup@hotmail.de).
}

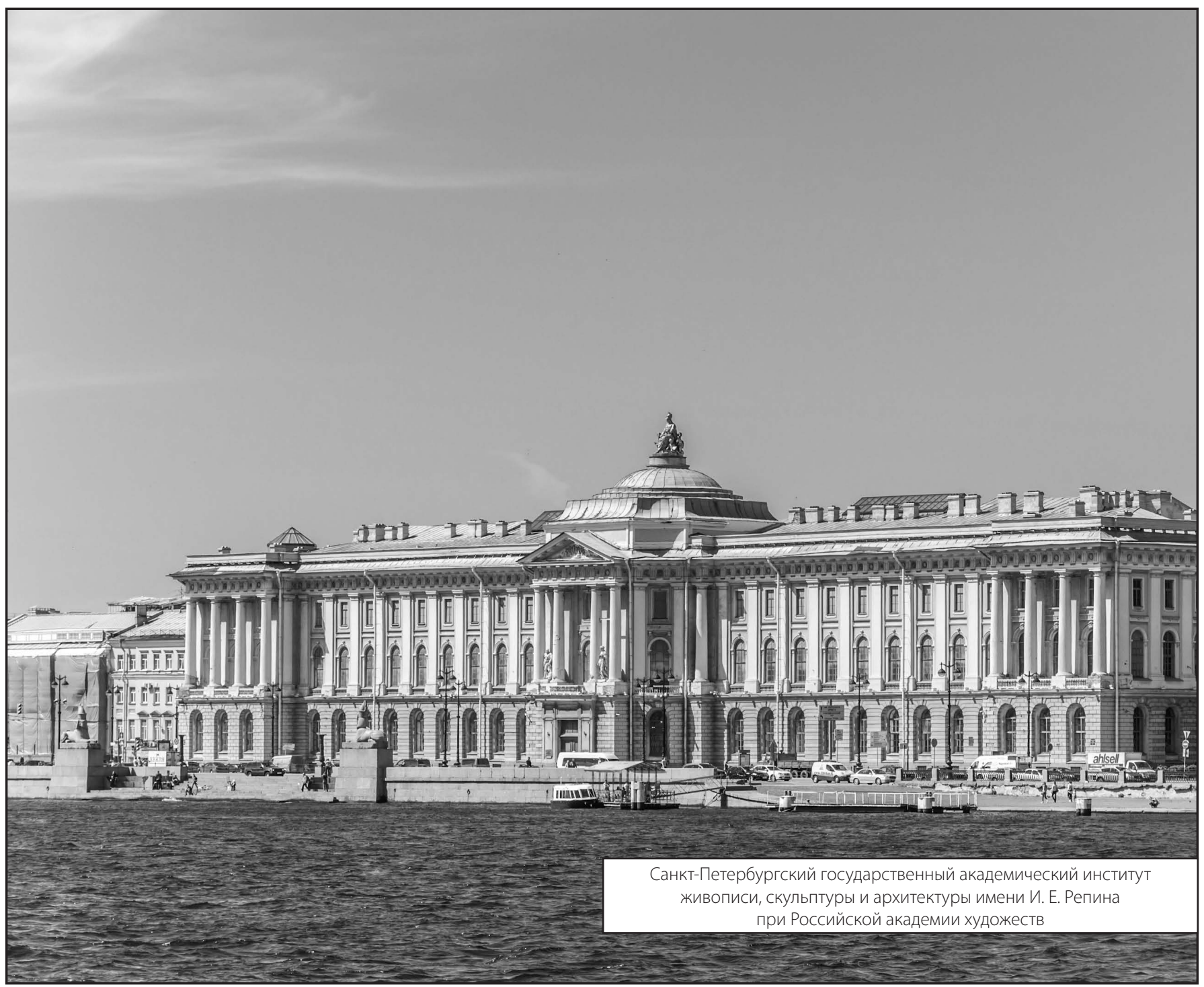

